\title{
Effects of Acidified Yeast and Whey Powder on Performance, Organ Weights, Intestinal Microflora, and Gut Morphology of Male Broilers
}

\section{-Author(s)}

\author{
Kermanshahi $\mathrm{H}^{\prime}$ \\ Heravi RM' \\ Attar A' \\ Abbasi Pour AR' \\ Bayat E" \\ Hossein Zadeh $M$ \\ Daneshmand A \\ Ibrahim SA"II
}

Department of Animal Science, Faculty of Agriculture, Ferdowsi University of Mashhad, Mashhad, Iran;

" Department of Animal Science, Faculty of Agriculture, University of Birjand, Birjand, South Khorasan, Iran;

III Food and Nutritional Science Program, North Carolina A\&T State University, Greensboro, North Carolina 27411, USA

\section{ABSTRACT}

In the present study, we investigated the effects of acidified dried whey and acidified yeast product and their combination on broiler growth characteristics, intestinal microflora and gut morphology. Seven hundred and fifty day-old Ross 308 male broilers were fed one of 10 dietary treatments with 5 replicates in a randomized design. A cornsoybean meal based diet (control group) was supplemented with 3 levels $(0.15,0.30$ and $0.45 \%)$ of acidified whey powder (AW), acidified yeast product (AY), and acidified whey powder and yeast product (AWY). Acidified yeast product improved ADG and FCR at $d 42$, but the effects of additives on productive performance were not significant across the entire rearing period. The highest level of AY increased the population of Lactobacillus spp., decreased that of E. coli and did not affect the bacterial total count at d 42 . Birds fed $0.45 \%$ AY showed higher villus height and better gut morphology compared to control birds. In conclusion, acidified yeast product increased the population of Lactobacillus, inhibited the growth of E. coli and improved gut morphology and structure, but did not affect growth performance and relative organ weight.

\section{INTRODUCTION}

The use of antibiotics as growth promoters has become a major concern to poultry product consumers due to emerging antibioticresistant strains of microbiota (Saleha et al., 2009). As a result, researchers have been working on appropriate antibiotic substitutes. This has led to the introduction of several alternatives for the poultry industry. Among these alternatives, additives such as yeast products, whey powder and organic acids have been examined due to their non-residual and non-resistant properties (Kim et al., 2014). The beneficial effects of yeast, whey and acidifiers as growth promoters and immune enhancers have already been demonstrated (Gao et al., 2008; Szczurek et al., 2013; Ricke, 2003). For example, yeast product, which contains high amounts of mannan chains (Roto et al., 2015), is a basic component of some commercially available prebiotics and has been shown to improve body weight gain, feed conversion ratio and immune response in broilers (Gao et al., 2008). Whey, another known additive that is a source of different nutrients such as proteins and carbohydrates (Szczurek et al., 2013) is also a source of lactose. Although birds have no enzyme for the digestion of lactose, the microflora of host birds utilize lactose to produce short chain fatty acids which lower the $\mathrm{pH}$ in the gut which favors a beneficial microbiome that is inhospitable to detrimental bacteria (Calik \& Ergun, 2015). Acidifiers comprise the other group of additives that have no side effects on host animals or consumers. Acidifiers 
Kermanshahi H, Heravi RMZ, Attar A, Pour ARA, Bayat B, Hossein Zadeh M, Daneshmand A, Ibrahim SA
Effects of Acidified Yeast and Whey Powder on Performance, Organ Weights, Intestinal Microflora, and Gut Morphology of Male Broilers can suppress the growth of pathogenic bacteria such as Campylobacter spp., Salmonella spp. and E. coli, stimulate the growth of beneficial microflora and ensure the digestive enzymes function at maximum capacity (Ricke, 2003; Dibner, 2004; Kim et al., 2014).

Since the beneficial properties of yeast cell wall and whey powder have been previously investigated, many studies demonstrated that acidic environment in the gut could improve the health benefits and functionality of these additives (Chen et al., 1996; Almajano et al., 2007). beneficially affect productive and physiological parameters in the chickens. While there has been very little research on such combinations, the objective of this study was to evaluate the effects of different inclusion levels of acidified whey powder, yeast product and their combination on the growth, internal organ weight, intestinal morphology and microflora of broilers.

\section{MATERIALS AND METHODS}

\section{Experimental diets, housing and condi- tions}

Seven hundred and fifty day-old Ross 308 male broiler chicks were randomly assigned to 10 treatments with 5 replicates of 15 birds in each replicate. A cornsoybean meal based diet was used as the control group that met or exceeded the requirements of Ross 308 male broiler chickens (Table 1). The test products were added to the basal diet at the expense of corn as follows: three levels $(0.15,0.30$ and $0.45 \%)$ of acidified whey powder (AW), three levels $(0.15,0.30$ and $0.45 \%$ ) of acidified yeast product (AY) and three levels $(0.15,0.30$ and $0.45 \%)$ of acidified whey powder and yeast product (AWY) (50:50 of each test product). Acidified whey powder ${ }^{1}$ and acidified yeast ${ }^{2}$ product were obtained from local companies. Birds had free access to feed and water during the entire experiment (0-42 days), and the illumination program was 23L/1D. The room temperature was $35^{\circ} \mathrm{C}$ on the first day and gradually was decreased to $22^{\circ} \mathrm{C}$ at 21 days of age and then kept constant to the end of the experimental period. All ten dietary treatments in starter (0-10 days), growing (11-24) and finishing (25-42) periods were isocaloric and isonitrogenous. Experimental protocols were approved by the Animal Care Committee of the Ferdowsi University of Mashhad, Iran.

Paloud Co., Neishabour, Khorasan Razavi, Iran. 2 Iran Malas Co., Fariman, Khorasan Razavi, Iran.
Table 1 - Ingredients and composition of basal diets ${ }^{1}$.

\begin{tabular}{|c|c|c|c|}
\hline Ingredients (g/kg) & $\begin{array}{l}\text { Starter } \\
(0-10)\end{array}$ & $\begin{array}{l}\text { Grower } \\
(11-24)\end{array}$ & $\begin{array}{l}\text { Finisher } \\
(25-42)\end{array}$ \\
\hline Maize & 497.1 & 508.9 & 571.7 \\
\hline Soybean meal (440 g/kg) & 402.2 & 382.8 & 324.5 \\
\hline Soybean oil & 51.3 & 67.3 & 63.6 \\
\hline Limestone & 11.7 & 09.6 & 9.3 \\
\hline Dicalcium phosphate & 21.7 & 18.9 & 17.7 \\
\hline Salt & 3.5 & 3.5 & 3.5 \\
\hline Vit. \& Min. Premixes² & 5.0 & 5.0 & 5.0 \\
\hline DL-Methionine & 3.9 & 2.9 & 2.5 \\
\hline L-Threonine & 0.6 & - & - \\
\hline L-Lysine & 3.0 & 1.2 & 1.1 \\
\hline \multicolumn{4}{|l|}{ Calculated analysis (\%) } \\
\hline ME (MJ/kg) & 12.7 & 13.2 & 13.4 \\
\hline Crude protein (g/kg) & 220.0 & 210.0 & 190.0 \\
\hline Calcium (g/kg) & 10.5 & 9.0 & 8.5 \\
\hline Available Phosphorous (g/kg) & 5.0 & 4.5 & 4.2 \\
\hline Sodium (g/kg) & 1.6 & 1.6 & 1.6 \\
\hline Arginine $(\mathrm{g} / \mathrm{kg})$ & 14.5 & 13.9 & 12.3 \\
\hline Lysine (g/kg) & 14.3 & 12.4 & 10.9 \\
\hline Methionine $(\mathrm{g} / \mathrm{kg})$ & 7.2 & 6.1 & 5.5 \\
\hline Methionine + Cystine $(\mathrm{g} / \mathrm{kg})$ & 10.7 & 9.5 & 8.6 \\
\hline Threonine (g/kg) & 9.4 & 8.6 & 7.8 \\
\hline Tryptophan (g/kg) & 3.3 & 3.1 & 2.7 \\
\hline
\end{tabular}

a1Acidified yeast product (150, 300 and $450 \mathrm{mg} / \mathrm{kg}$ ), acidified whey (150, 300 and 450 $\mathrm{mg} / \mathrm{kg}$ )and their combination $(150,300$ and $450 \mathrm{mg} / \mathrm{kg}$ ) were added as a replacement for maize.

${ }^{2}$ Vitamin and mineral premix supplied per kilogram of diet: vitamin A: 10000 IU; vita-

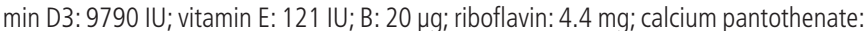
$40 \mathrm{mg}$; niacin: $22 \mathrm{mg}$; choline:840 mg; biotin: $30 \mu g$; thiamin, 4 mg; zinc sulfate, 60 $\mathrm{mg}$; manganese oxide, $60 \mathrm{mg}$.

\section{Growth performance and carcass traits}

Birds were weighed on arrival and on d 10, 24 and 42 to determine average daily gain (ADG). Residual feed from each pen unit was collected and weighed on d 10, 24 and 42 to measure feed intake (FI). Obtained data were used to calculate the feed conversion ratio (FCR). Mortality was recorded daily and used to adjust performance parameters. At days 24 and 42, ten birds from each treatment (two from each replicate) were randomly selected, weighed and euthanized by cervical dislocation. Internal organs (heart, liver, spleen, pancreas, bursa of Fabricius and fat pad) were removed and the relative weights (to live body weight) were measured.

\section{Ileal microbial content}

The whole content of ileum was collected, mixed and $1 \mathrm{~g}$ of fresh sample was collected in sampling cups to determine the total bacterial populations of Escherichia coli (E. coli), and Lactobacillus spp. Ileal 
Kermanshahi H, Heravi RMZ, Attar A, Pour ARA, Bayat B, Hossein Zadeh M, Daneshmand A, Ibrahim SA
Effects of Acidified Yeast and Whey Powder on Performance, Organ Weights, Intestinal Microflora, and Gut Morphology of Male Broilers contents were serially diluted 10 -fold from $10^{-1}$ to $10^{-7}$ with sterile physiological saline and subsequently homogenized for $3 \mathrm{~min}$. Dilutions were then plated on a selective agar medium for enumeration. Lactobacilli was anaerobically assayed using Lactobacilli MRS agar and incubated at $37^{\circ} \mathrm{C}$ for $48 \mathrm{~h}$. E. coli counts were performed on McConkey agar and incubated for $24 \mathrm{~h}$ at $37^{\circ} \mathrm{C}$. After incubation, colonies formed on the respective media were counted and expressed as Log (CFU) per g of intestinal content (Guban et al., 2006). All microbiological analyses were performed in triplicate, and average values were used for statistical analyses.

\section{Gut histomorphology}

In order to evaluate the intestinal morphology, the jejunum segment (between the end of duodenal loop to Meckel's diverticulum) was separated from the whole intestine, cleaned from adherent materials and gently squeezed to empty from digesta. Next, $2 \mathrm{~cm}$ of jejunum segment was kept in a 10\% formaldehyde phosphate buffer for $48 \mathrm{~h}$, then embedded in paraffin, cut into $5 \mu \mathrm{m}$ sections using a microtome (Leica HI1210, Leica Microsystems Ltd., Wetzlar, Germany). The prepared section was placed on a glass slide, stained with hematoxylin and eosin and examined with an optical microscope (Olympus BX41TF, Olympus Corporation, Tokyo, Japan). A total of 10 villi were measured per slide and 5 slides were prepared from each jejunal segment per bird (50 villi per bird; 10 birds/treatment). The average slide measurements per sample was expressed as a mean for each bird. Villus width (VW), villus height $(\mathrm{VH})$, crypt depth (CD), mucosal layer thickness (MLT) and villus surface area
(VSA) were measured in each sample using a digital camera (Olympus DP12 U-TV0.5 XC-2, Olympus Corporation, Tokyo, Japan) and an image analyzing software (Olysia Soft Imaging System, Germany) which were installed on the microscope.

\section{Statistical analysis}

All data were analyzed using SAS (2004) one way ANOVA. Differences between means were compared using Tukey's test, and P-values less than 0.05 were considered significant.

\section{RESULTS}

\section{Growth and organ relative weight}

The effects of experimental diets on growth performance are summarized in Table 2. The levels of $A W, A Y$ and $A W Y$ had no significant effect on ADG, $\mathrm{FI}$ and FCR at 0-10 days of age. However, ADG and FCR were significantly affected by dietary treatments at 11-24 days of age, and the highest ADG and lowest FCR were at $0.45 \%$ AY. During the growing period, the highest level of $A Y$ increased $(p<0.05) A D G$ and improved FCR compared to the control group. By increasing the level of additives to $0.45 \%$, experimental diets numerically increased ADG and improved FCR in comparison to the control group. During the finishing period, birds fed with higher levels of AY (i.e. $0.30 \%$ and $0.45 \%)$ showed better $(p<0.05)$ FCR compared to birds on the control diet. The analysis of performance data for the overall period showed that experimental additives did not affect ADG, AFI and FCR when compared to the control group.

Table 2 - Effects of treatments on growth performance in broilers from 0-42 days of age.

\begin{tabular}{|c|c|c|c|c|c|c|c|c|c|c|c|c|c|}
\hline \multirow[b]{2}{*}{ Treatments } & \multirow[b]{2}{*}{$\%$} & \multicolumn{3}{|c|}{ 0-10 days (Starter) } & \multicolumn{3}{|c|}{ 11-24 days (Grower) } & \multicolumn{3}{|c|}{ 25-42 days (Finisher) } & \multicolumn{3}{|c|}{$0-42$ days } \\
\hline & & $\mathrm{AFI}^{1}$ & ADG & FCR & $\mathrm{AFI}$ & ADG & FCR & $\mathrm{AFI}$ & ADG & FCR & $\mathrm{AFI}$ & ADG & FCR \\
\hline Control $^{2}$ & - & 28.7 & 24.0 & 1.19 & 70.7 & $40.4^{\text {bc }}$ & $1.75^{\mathrm{ab}}$ & 167.4 & 89.8 & $1.86^{\mathrm{ab}}$ & 98.2 & 55.5 & 1.76 \\
\hline \multirow[t]{3}{*}{ AW } & 15 & 29.9 & 23.8 & 1.25 & 71.7 & $38.8^{c}$ & $1.85^{\mathrm{a}}$ & 157.4 & 90.0 & $1.74^{c}$ & 94.8 & 55.0 & 1.72 \\
\hline & 30 & 28.9 & 23.0 & 1.26 & 71.5 & $40.7^{b c}$ & $1.75^{\mathrm{ab}}$ & 159.5 & 91.4 & $1.74^{c}$ & 95.2 & 56.0 & 1.70 \\
\hline & 45 & 29.8 & 24.7 & 1.21 & 72.4 & $42.7^{\mathrm{abc}}$ & $1.70^{\mathrm{abcd}}$ & 165.3 & 91.0 & $1.81^{\mathrm{abc}}$ & 98.1 & 56.9 & 1.72 \\
\hline \multirow[t]{3}{*}{ AY } & 15 & 29.9 & 24.2 & 1.23 & 69.5 & $40.0^{\mathrm{bc}}$ & $1.73^{\mathrm{abc}}$ & 158.7 & 87.1 & $1.82^{\mathrm{abc}}$ & 94.5 & 54.3 & 1.74 \\
\hline & 30 & 30.6 & 24.6 & 1.24 & 73.4 & $43.6^{a b}$ & $1.68^{\mathrm{abcd}}$ & 156.5 & 90.2 & $1.73^{c}$ & 95.1 & 56.9 & 1.67 \\
\hline & 45 & 29.4 & 22.9 & 1.28 & 71.1 & $45.6^{a}$ & $1.56^{d}$ & 158.4 & 90.8 & $1.74^{c}$ & 94.8 & 57.4 & 1.65 \\
\hline \multirow[t]{3}{*}{ AWY } & 15 & 30.1 & 25.1 & 1.20 & 75.6 & $42.8^{\mathrm{abc}}$ & $1.77^{\mathrm{ab}}$ & 166.4 & 92.1 & $1.80^{b c}$ & 99.7 & 57.5 & 1.73 \\
\hline & 30 & 28.9 & 24.6 & 1.23 & 68.3 & $43.2^{\mathrm{ab}}$ & $1.57^{\mathrm{cd}}$ & 160.0 & 88.9 & $1.8 b^{c}$ & 94.4 & 56.0 & 1.68 \\
\hline & 45 & 29.5 & 24.3 & 1.21 & 72.2 & $44.1^{\mathrm{ab}}$ & $1.64^{\mathrm{bcd}}$ & 165.5 & 87.0 & $1.90^{\mathrm{a}}$ & 98.0 & 55.7 & 1.76 \\
\hline p-value & & 0.74 & 0.41 & 0.27 & 0.77 & 0.03 & 0.01 & 0.40 & 0.94 & 0.005 & 0.47 & 0.76 & 0.08 \\
\hline SEM $^{3}$ & & 0.751 & 0.677 & 0.025 & 2.569 & 1.309 & 0.050 & 3.934 & 2.816 & 0.028 & 3.187 & 1.948 & 0.026 \\
\hline
\end{tabular}

1 AFI, average feed intake (g/bird); ADG: average daily gain (g/bird); FCR, feed conversion ratio (g/g).

2 Control, no added supplements; AW: Acidified whey powder; AY: Acidified yeast product; AWY: Acidified whey powder plus yeast product.

3 SEM: standard error of means.

a-d Means values with different superscripts within a column differ significantly $(p<0.05)$. 
Table 3 shows the effects of treatments on the relative weights of internal organs. Although the lowest levels of all additives numerically decreased the fat pad, none of the AY, AW and AWY affected the relative weights of internal organs compared to the control group.

Table 3 - Effects of treatments on relative internal organ weights (organ weight/live body weight $\times 100$ ) in male broilers from $0-42$ days of age.

\begin{tabular}{|c|c|c|c|c|c|c|c|}
\hline \multirow{2}{*}{ Treatments } & \multirow{2}{*}{$\%$} & \multicolumn{6}{|c|}{ Internal organs (\%) } \\
\hline & & Liver & Fat pad & Bursa of Fabricius & Spleen & Pancreas & Heart \\
\hline Control' $^{1}$ & - & 2.34 & 1.14 & 0.05 & 0.13 & 0.24 & 0.51 \\
\hline \multirow[t]{3}{*}{ AW } & 15 & 2.06 & 0.97 & 0.06 & 0.11 & 0.22 & 0.51 \\
\hline & 30 & 1.92 & 1.10 & 0.05 & 0.12 & 0.23 & 0.60 \\
\hline & 45 & 2.16 & 1.20 & 0.07 & 0.13 & 0.25 & 0.59 \\
\hline \multirow[t]{3}{*}{$0.54 \mathrm{AY}$} & 15 & 1.97 & 0.89 & 0.06 & 0.11 & 0.18 & 0.50 \\
\hline & 30 & 2.03 & 1.17 & 0.07 & 0.11 & 0.23 & 0.54 \\
\hline & 45 & 1.91 & 0.69 & 0.06 & 0.11 & 0.19 & 0.56 \\
\hline \multirow[t]{3}{*}{ AWY } & 15 & 2.17 & 0.75 & 0.07 & 0.11 & 0.23 & 0.59 \\
\hline & 30 & 2.15 & 1.18 & 0.05 & 0.12 & 0.22 & 0.53 \\
\hline & 45 & 2.38 & 1.30 & 0.05 & 0.12 & 0.21 & 0.58 \\
\hline$p$-value & & 0.613 & 0.381 & 0.917 & 0.955 & 0.489 & 0.951 \\
\hline $\mathrm{SEM}^{2}$ & & 0.180 & 0.193 & 0.064 & 0.074 & 0.082 & 0.064 \\
\hline
\end{tabular}

${ }^{1}$ Control, no added supplements; AW: Acidified whey powder; AY: Acidified yeast product; AWY: Acidified whey powder plus yeast product.

2 SEM: standard error of means (results are given as means $(n=10)$ for all treatments).

\section{Microbial enumeration}

Populations of E. coli and Lactobacillus spp. did not show significant differences among treatments at 24 days of age (Table 4); however, the number of total counts was lower $(p<0.05)$ for the highest (i.e. $0.45 \%$ ) levels of all supplemented diets when compared with the control diet at 24 days of age. At day 42, dietary treatments had no significant effect on the total number of counts but significantly affected the number of $E$. coli and Lactobacillus spp. The highest levels of AY and AWY decreased $(p<0.05)$ the number of $E$. coli when compared with control birds. The addition of $0.45 \%$ AY and AWY increased the number of Lactobacillus spp.in comparison to the control group, while other treatments had no significant effect on the number of Lactobacillus spp.

\section{Gut morphology}

The effects of dietary treatments on intestinal morphology of broilers at 24 days of age are shown in Table 5. The highest levels of AY and AWY significantly increased villus height compared to control birds. Although the level of $0.45 \%$ of AY and AWY increased the crypt depth and mucosal layer thickness, these differences were not significant in comparison to the control group. Neither villus width nor villus surface

Table 4 - Effects of treatments on ileal microbial counts (CFU/g, log 10) in broilers at 24 and 42 days of age.

\begin{tabular}{|c|c|c|c|c|c|c|c|}
\hline \multirow[b]{2}{*}{ Treatments } & \multirow[b]{2}{*}{$\%$} & \multicolumn{3}{|c|}{ Day 24} & \multicolumn{3}{|c|}{ Day 42} \\
\hline & & Total counts & E. coli & Lactobacillus spp. & Total counts & E. coli & Lactobacillus spp. \\
\hline Control $^{1}$ & - & $5.30^{\mathrm{ab}}$ & 3.81 & 3.73 & 4.75 & $4.02^{\mathrm{ab}}$ & $4.04^{b c}$ \\
\hline \multirow[t]{3}{*}{ AW } & 15 & $5.32^{\mathrm{ab}}$ & 4.65 & 4.45 & 5.60 & $4.16^{a}$ & $3.42^{c}$ \\
\hline & 30 & $5.50^{\mathrm{a}}$ & 4.70 & 4.34 & 5.25 & $3.75^{\mathrm{ab}}$ & $4.23^{\mathrm{ab}}$ \\
\hline & 45 & $4.66^{c}$ & 4.34 & 4.56 & 4.96 & $4.35^{\mathrm{a}}$ & $4.50^{\mathrm{ab}}$ \\
\hline \multirow[t]{3}{*}{$A Y$} & 15 & $5.00^{\mathrm{abc}}$ & 4.14 & 4.05 & 5.36 & $4.09^{a b}$ & $3.98^{b c}$ \\
\hline & 30 & $5.07^{a b c}$ & 4.01 & 3.82 & 4.77 & $4.00^{\mathrm{ab}}$ & $3.83^{b c}$ \\
\hline & 45 & $4.76^{c}$ & 3.81 & 3.91 & 5.12 & $3.36^{c}$ & $4.81^{a}$ \\
\hline \multirow[t]{3}{*}{ AWY } & 15 & $4.92^{b c}$ & 3.46 & 3.70 & 4.78 & $3.97^{a b}$ & $3.79^{b c}$ \\
\hline & 30 & $4.83^{b c}$ & 3.29 & 3.56 & 4.77 & $3.94^{\mathrm{ab}}$ & $3.79^{b c}$ \\
\hline & 45 & $4.60^{c}$ & 3.27 & 3.53 & 4.83 & $3.67^{b}$ & $4.96^{a}$ \\
\hline P-value & & 0.009 & 0.115 & 0.125 & 0.240 & 0.031 & 0.040 \\
\hline SEM $^{2}$ & & 0.161 & 0.379 & 0.276 & 0.251 & 0.307 & 0.308 \\
\hline
\end{tabular}

${ }^{1}$ Control, no added supplements; AW: Acidified whey powder; AY: Acidified yeast product; AWY: Acidified whey powder plus yeast product.

2 SEM: standard error of means (results are given as means $(n=10)$ for all treatments).

a-c Means values with different superscripts within a column differ significantly $(p<0.05)$. 
Kermanshahi H, Heravi RMZ,

Attar A, Pour ARA, Bayat B,

Hossein Zadeh M, Daneshmand A,

Ibrahim SA
Effects of Acidified Yeast and Whey Powder on Performance, Organ Weights, Intestinal Microflora, and Gut Morphology of Male Broilers

Table 5 - Effects of treatments on jejunal morphology in broilers at 24 and 42 days of age.

\begin{tabular}{|c|c|c|c|c|c|c|c|c|c|c|c|}
\hline \multirow[b]{2}{*}{ Treatments } & \multirow[b]{2}{*}{$\%$} & \multicolumn{5}{|c|}{ Day 24} & \multicolumn{5}{|c|}{ Day 42} \\
\hline & & $\begin{array}{l}\mathrm{VH}^{2} \\
(\mu \mathrm{m})\end{array}$ & $\begin{array}{l}\text { VW } \\
(\mu \mathrm{m})\end{array}$ & $\begin{array}{c}C D \\
(\mu \mathrm{m})\end{array}$ & $\begin{array}{l}\text { MLT } \\
(\mu \mathrm{m})\end{array}$ & $\begin{array}{l}\text { VSA } \\
\left(\mu m^{2}\right)\end{array}$ & $\begin{array}{l}\mathrm{VH} \\
(\mu \mathrm{m})\end{array}$ & $\begin{array}{l}\mathrm{VW} \\
(\mu \mathrm{m})\end{array}$ & $\begin{array}{l}C D \\
(\mu \mathrm{m})\end{array}$ & $\begin{array}{l}\text { MLT } \\
(\mu \mathrm{m})\end{array}$ & $\begin{array}{l}\text { VSA } \\
\left(\mu m^{2}\right)\end{array}$ \\
\hline Control $^{1}$ & - & $842.7^{c}$ & 101.5 & $198.3^{\mathrm{abc}}$ & $1121.2^{\mathrm{ab}}$ & 266546 & $1029.2^{b c}$ & 107.3 & $199.0^{b}$ & $1262.8^{c}$ & 349973 \\
\hline \multirow[t]{3}{*}{ AW } & 15 & $867.0^{\text {bc }}$ & 100.6 & $191.0^{\mathrm{abc}}$ & 1074. $9^{a b}$ & 285264 & $1010.5^{b c}$ & 109.9 & $214.6^{b}$ & $1255.7^{c}$ & 326891 \\
\hline & 30 & $871.7^{\mathrm{bc}}$ & $113.9 b$ & $190.1^{\mathrm{abc}}$ & $1126.3^{a b}$ & 308625 & $1016.5^{b c}$ & 117.3 & $294.2^{\mathrm{ab}}$ & $1354.0^{c}$ & 536257 \\
\hline & 45 & $898.4^{b c}$ & 92.6 & $177.1^{\mathrm{bcd}}$ & $1224.4^{a}$ & 291844 & $1117.8^{\mathrm{abc}}$ & 106.4 & $244.1^{a b}$ & $1407.3^{b c}$ & 371484 \\
\hline \multirow[t]{3}{*}{ AY } & 15 & $836.2^{c}$ & 97.7 & $198.5^{\mathrm{abc}}$ & $1075.4^{\mathrm{ab}}$ & 254808 & $1163.2^{\mathrm{abc}}$ & 111.9 & $231.8^{\mathrm{ab}}$ & $1433.6^{b c}$ & 405335 \\
\hline & 30 & $866.3^{b c}$ & 102.8 & $141.6^{d}$ & $1032.4^{b}$ & 273610 & $999.1^{b c}$ & 99.8 & $187.0^{\mathrm{b}}$ & $1224.0^{c}$ & 312128 \\
\hline & 45 & $1026.3^{a}$ & 117.9 & $200.1^{\mathrm{abc}}$ & $1218.6^{a}$ & 234866 & $1456.2^{a}$ & 154.9 & $325.4^{\mathrm{a}}$ & $1841.3^{a}$ & 542592 \\
\hline \multirow[t]{3}{*}{ AWY } & 15 & $836.9^{c}$ & $99.6 c$ & $156.9^{c d}$ & $1032.1^{b}$ & 322858 & $960.5^{c}$ & 107.1 & $227.8^{\mathrm{ab}}$ & $1129.6^{c}$ & 322900 \\
\hline & 30 & $872.2^{\mathrm{bc}}$ & 95.3 & $154.5^{c d}$ & $1131.7^{\mathrm{ab}}$ & 286465 & $1365.3^{\mathrm{ab}}$ & 95.4 & $284.3^{\mathrm{ab}}$ & $1331.5^{c}$ & 408352 \\
\hline & 45 & $1000.9^{a b}$ & 112.4 & $218.2^{\mathrm{ab}}$ & $1211.5^{a}$ & 314809 & $1146.9^{\mathrm{abc}}$ & 86.2 & $210.4^{b}$ & $1757.8^{\mathrm{ab}}$ & 310047 \\
\hline P-value & & 0.0003 & 0.564 & 0.0009 & 0.037 & 0.708 & 0.0006 & 0.646 & $<0.0001$ & $<0.0001$ & 0.724 \\
\hline $\mathrm{SEM}^{3}$ & & 44.29 & 8.39 & 14.21 & 48.21 & 9031.3 & 76.71 & 23.72 & 23.23 & 83.30 & 9808.4 \\
\hline
\end{tabular}

${ }^{1}$ Control, no added supplements; AW: Acidified whey powder; AY: Acidified yeast product; AWY: Acidified whey powder plus yeast product.

${ }^{2} \mathrm{VH}$ : villus height; VW: Villus width; CD: Crypt depth; MLT: Mucosal layer thickness, VSA: villus surface area.

${ }^{3}$ SEM: standard error of means (results are given as means $(n=10)$ for all treatments).

${ }^{a-c}$ Means values with different superscripts within a column differ significantly $(p<0.05)$.

area was affected by additional levels of dietary supplements.

Birds receiving the highest level of $A Y$ showed higher $(p<0.05)$ villus height and crypt depth in comparison to birds fed the control diet, while other treatments were not effective at day42. The highest levels of AY and AWY increased $(p<0.05)$ mucosal layer thickness compared to the control group, while other treatments had no significant effect on mucosal layer thickness. None of the dietary treatments significantly affected villus width and villus surface area.

\section{DISCUSSION}

The emergence of antibiotic-resistant strains of bacteria has prompted the scientific community to search for alternative approaches to the use of antibiotics. As a result, additives such as whey, yeast products and acidifiers have been introduced as replacements for antibiotics. Since these additives have the same beneficial effects on various parameters, it could be hypothesized that a product containing the mixture of these additives might result in synergistic effects and subsequently reinforce favorable outcomes. In the present study, the effects of acidified yeast product, acidified whey powder and their combination on broilers health and production attributes were examined.

ADG and FCR improved in birds fed with acidified yeast product. There is very limited data regarding the supplementary effects of acidified additives on poultry performance. Gao et al. (2008) reported that growth performance and immune modulatory functions improved in broilers fed with yeast product. It has been shown that yeast product contains beneficial nutrients such as peptides, oligosaccharides, flavors and aroma substances which increase nutrient digestibility, enhance the growth of beneficial bacteria such as Lactobacillus and improve gut immunity against pathogens (Roto et al., 2015). Adil et al. (2010) supplemented broiler diets with various levels of different organic acids to evaluate the effects of acidifiers on productive performance and gut morphology. They concluded that acidifiers enhanced growth performance and gut health and morphology in broilers, irrespective of the type and levels of organic acids. It has been demonstrated (Rocke, 2003; Dibner, 2004) that acidifiers can also decrease intestinal $\mathrm{pH}$ which results in an increase in beneficial bacteria and a decrease in pathogenic ones. Given this result, the overlap of favorable attributes of acidifiers and yeast product in an acidified yeast product might boost the individual effects of these additives and thereby improve the birds' growth performance. Bozkurt et al. (2009) reported that the supplementary effects of prebiotics and acidifiers improved the body weight and FCR of broilers when compared to the birds in the control group, which is in consistent with results of the present study. Previous studies have reported that whey powder provided favorable nutrients for animals such as balanced amino acids, had a high protein efficiency ratio and was a rich source of carbohydrates, especially lactose (Szczurek et al., 2013). However, the acidified whey powder did not affect performance during any rearing period, which is in agreement with previous results (Gülşen et al., 2002). 
Kermanshahi H, Heravi RMZ, Attar A, Pour ARA, Bayat B, Hossein Zadeh M, Daneshmand A, Ibrahim SA
Effects of Acidified Yeast and Whey Powder on Performance, Organ Weights, Intestinal Microflora, and Gut Morphology of Male Broilers
Since AY treatment tended to decrease the fat pad at 42 days of age, none of the experimental diets affected the relative weight of organs. Previous studies also showed that the individual inclusion of yeast product, whey powder and acidifiers did not affect internal organ relative weights (Santos et al., 2002; Fritts \& Waldroup, 2003). This is consistent with the present results which showed that experimental additives had no toxic or hypertrophic effects on selected organs.

AY statistically decreased the total bacterial population at day 24 and significantly increased Lactobacillus spp. and lowered E. coli at 42 days of age. Previous studies have shown that the inclusion of yeast product in broiler diets can increase the number of health-promoting bacteria like lactobacillus spp. (Roto et al., 2015) and decrease the number of pathogenic microbiota such as Clostridium (Yitbarek et al., 2012) and E. coli (Huff et al., 2007). In addition, some researchers (Dibner, 2004; Kim et al., 2014) have suggested that acidifiers can decrease the intestinal $\mathrm{pH}$ and maintain acidic conditions in the gut environment. This change in the environment would favor acidophilic bacteria which can prevent the attachment of pathogenic bacteria to epithelial cells through the competitive exclusion principle and yeast product in an acidified yeast product might boost the individual effects of these additives and thereby improve the birds' growth performance. Bozkurt et al. (2009) reported that the supplementary effects of prebiotics and acidifiers improved the body weight and FCR of broilers when compared to the birds in the control group, which is in consistent with results of the present study. Previous studies have reported that whey powder provided favorable nutrients for animals such as balanced amino acids, had a high protein efficiency ratio and was a rich source of carbohydrates, especially lactose (Szczurek et al., 2013). However, the acidified whey powder did not affect performance during any rearing period, which is in agreement with previous results (Gülşen et al., 2002).

Since AY treatment tended to decrease the fat pad at 42 days of age, none of the experimental diets affected the relative weight of organs. Previous studies also showed that the individual inclusion of yeast product, whey powder and acidifiers did not affect internal organ relative weights (Santos et al., 2002; Fritts \& Waldroup, 2003). This is consistent with the present results which showed that experimental additives had no toxic or hypertrophic effects on selected organs. AY statistically decreased the total bacterial population at day 24 and significantly increased Lactobacillus spp. and lowered
E. coli at 42 days of age. Previous studies have shown that the inclusion of yeast product in broiler diets can increase the number of health-promoting bacteria like lactobacillus spp. (Roto et al., 2015) and decrease the number of pathogenic microbiota such as Clostridium (Yitbarek et al., 2012) and E. coli (Huff et al., 2007). In addition, some researchers (Dibner, 2004; Kim et al., 2014) have suggested that acidifiers can decrease the intestinal $\mathrm{pH}$ and maintain acidic conditions in the gut environment. This change in the environment would favor acidophilic bacteria which can prevent the attachment of pathogenic bacteria to epithelial cells through the competitive exclusion principle and consequently deplete more pathogens. Thus, it could be inferred that the acidification of yeast products intensified the individual effects of each acidifier and yeast product and led to the inclination of gut microbiota toward beneficial bacteria. Kermanshahi \& Rostami (2006) reported that the addition of whey powder at various levels significantly increased the total population in the ceca during 1-14 days of age, yet the acidified whey powder in the present study had no effect on gut microflora.

The acidified yeast product improved intestinal morphology, especially villus height and crypt depth, at 24 and 42 days of age. Rahbar et al. (2011) added yeast product to broiler diets and reported that yeast product could improve villi attributes and enhance gut morphometry. Paul et al. (2007) reported that acidifiers increased villus height and width and improved gut histomorphology in broilers. In addition, Kien et al. (2007) proposed that acidifiers, especially butyric acid, might be a source of energy for the villi of the intestine to support the growth and development of the gut structure and better nutrient absorption. As a result, adding acidified yeast product to broilers' diet would primarily decrease the colonization of $E$. coli in the gut and maintain growth and development of villi lead to the improvement of gut morphology.

\section{CONCLUSION}

The present results confirmed that a combination of additives, especially acidified yeast product, may have beneficial effects on various parameters in broilers. Acidified yeast product increased the population of Lactobacillus spp., decreased the number of E. coli, and improved villus height and gut morphology. More research is warranted in order to determine the appropriate concentrations and levels of organic acids and yeast product when the two are combined. 
Kermanshahi H, Heravi RMZ,

Attar A, Pour ARA, Bayat B,

Hossein Zadeh M, Daneshmand A,

Ibrahim SA

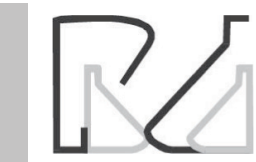

Effects of Acidified Yeast and Whey Powder on

Performance, Organ Weights, Intestinal Microflora, and Gut Morphology of Male Broilers

\section{ACKNOWLEDGEMENTS}

The authors would like to thank Ferdowsi University of Mashhad, Iran, for its financial support of this project (No. 2/21397).

\section{REFERENCES}

Adil S, Banday T, Ahmad Bhat G, SaleemMir M, Rehman M. Effect of dietary supplementation of organic acids on performance, intestinal histomorphology, and serum biochemistry of broiler chicken. Veterinary Medicine International; 2010. http://doi.org/ urn:doi:10.4061/2010/479485.

Bozkurt M, Kucukyimaz K, Cath AU, Cinar M. The effect of single or combined dietary supplementation of prebiotics, organic acid and probiotics on performance and slaughter characteristics of broilers. South African Journal of Animal Science 2009;39:197-204.

Calik A, Ergun A. Effect of lactulose supplementation on growth performance, intestinal histomorphology, cecal microbial population, and short-chain fatty acid composition of broiler chickens. Poultry Science 2015;94:2173-2182.

Dibner J. Organic acids: can they replace antibiotic growth promoters? Feed International 2004;25:14-16.

Fritts CA, Waldroup PW. Evaluation of mannan oligosaccharide as a replacement for growthpromoting antibiotics in diets for turkeys. International Journal of Poultry Science 2003;2:19-22.

Gao J, Zhang HJ, Yu SH, Wu SG, Yoon I, Quigley J, et al. Effects of Yeast Culturein Broiler Diets on Performance and Immunomodulatory Functions. Poultry Science 2008;87:1377-1384.

Guban J, Korver DR, Allison GE, Tannock GW. Relationship of dietary antimicrobial drug administration with broiler performance, decreased population levels of Lactobacillus salivarius, and reduced bile salt deconjugation in the ileum of broiler chickens. Poultry Science 2006;85:2186-2194

Gülsen N, Coskun HD, Umucaliar Fl, Boydak M. Effect of lactose and dried whey supplementation on growth performance and history of the immune system in broilers. Archives of Animal Nutrition 2002;56:131139.

Huff GR, Huff WE, Rath NC, Santos FS, Farnell MB, Donoghue AM. Influence ofhen age on the response of turkey poults to cold stress, Escherichia coli challenge, and treatment with a east extract antibiotic alternative. Poultry Science 2007;86:636-642.
Kermanshahi $\mathrm{H}$, Rostami $\mathrm{H}$. Influence of supplemental dried whey on broiler performance and cecal flora. International Journal of Poultry Science 2006;5:538-543.

Kien CL, Blauwiekel R, Bunn JY, Jetton TL, Frankel WL, Holst JJ. Cecal infusion of buty rate increases intestinal cell proliferation in piglets. Journal of Nutrition 2007;137:916-922.

Kim DW, Kim JH, Kang HK, Akter N, Kim MJ, Na JC, et al. Dietary supplementation of phenyllactic acid on growth performance, immune response, cecal microbial population, and meat quality attributes of broiler chickens. Journal of Applied Poultry Research 2014;23:661670.

Rahbar MG, Farhoomand P, Kamyab A. The effect of different concentrations of Peganum harmala seeds with or without a yeast cell wall product on the live performance, intestinal histomorphology, and weights of visceral organs of broiler chickens. Journal of Applied Poultry Research 2011;20:454-462

Ricke SC. Perspective on the use of organic acids and short chain fatty acids as antimicrobials. Poultry Science 2003;82:632-639.

Roto SM, Rubinelli PM, Ricke SC. An introduction to the avian gut microbiota and the effects of yeast based prebiotic-type compounds as potential feed additives. Frontiers in Veterinary Science 2015;2:28.

Saleha AA, Miyang TT, Ganapathy KK, Zulkifli I, Raha R, Arifah K. Possible effect of antibiotic supplemented feed and environment on the occurrence of multiple antibiotic resistant E. coli in chickens. International Journal of Poultry Science 2009;8:28-31.

Santos EC, Teixeira AS, Bertechini AG, Freitas RTF, Rodrigues PB, Dias ES, et al. Effect of growth beneficial additives on broiler carcass yield. Proceeding of Brazilian Society of Animal Production 2002; p. 5.

SAS. Statistical analysis systems user's guide. 9.1 ed. Raleigh: SAS Institute; 2005

Szczurek W, Szymczyk B, Arczewska-Włosek A, Józefiak D, Alloui MN The effects of dietary whey protein concentrate level on performance, selected intestinal tract and blood parameters, and thiobarbituric acid reactive substances in the liver and breast meat of broiler chickens. Journal of Animal and Feed Sciences 2013;22:342-353.

Yitbarek A, Echeverry $\mathrm{H}$, Brady J, Hernandez-Doria J, Camelo-Jaimes G Sharif $S$, et al. Innate immune response to yeast-derived carbohydratesin broiler chickens fed organic diets and challenged with Clostridium perfringens. Poultry Science 2012;91:1105-1112. 
